\title{
Not Just Bricks and Mortar
}

\author{
Report of the Royal College of Psychiatrists Working Party on \\ the Size, Staffing, Structure, Siting, and Security of New Acute \\ Adult Psychiatric In-Patient Units
}

\author{
Tom Burns
}

The past 40 years have seen momentous changes in the delivery of mental health care in the UK, with a reduction of in-patient beds by over two-thirds. This shift in the location of treatment from institutions to the communities they serve has seen an enormous growth in writing and research on community initiatives. During this time, however, the equally profound changes in both pressure on, and practice within, in-patient units have been relatively neglected. This is despite the repeated recognition that high-quality in-patient provision is a core component of virtually all community mental health demonstration services - whether home-based nursing in Birmingham, assertive community treatment in Wisconsin or postItalian reform South Verona.

The Royal College of Psychiatrists set up a working party to summarise current thinking on best practice for the design and planning of new adult acute in-patient units. It was hoped that such a report would be of practical value to those planning new provision. Although a College working party, it had support from the Department of Health and active involvement from the Royal College of Nursing, UNISON, National Association of Health Authorities and Trusts (later the NHS Confederation) and the NHS Estates. The working party met on nine occasions between February 1996 and October 1997. when the report was submitted to Council. The 60 page report (Council Report CR62) consists of eight chapters and ends with detailed recommendations. It is available from the College Book Sales Office for £7.50. Its main findings are summarised here.

There is no evidence-based canon for planning an in-patient unit, nor is there any perfect plan that will suit all circumstances. Nevertheless the report drew a series of conclusions (often finely balanced) and advises the importance of early involvement of clinicians and user groups in the planning process to draw on common themes and to reflect local circumstances. As local circumstances can be so different the guidelines assume a stand-alone, adult, in-patient unit the impact of special patient groups or services could not be quantified and is not explored.

The requirements of adequate staffing and security constrain the generalisability of ultrasmall, stand-alone units. Modern in-patient units must tolerate high levels of compulsory admissions and disturbance, and therefore need resident junior doctors and higher levels of welltrained nurses than is often the case at present. Less than 45 beds is unlikely to be viable and we have suggested that this should represent at least three wards and serve at least five community mental health teams. Clearly there is a trade-off between a minimum safe size lensuring patients are not kept unnecessarily in secure units) and local accessibility in more thinly populated areas. Assuming a single point of entry, more than about five wards risks becoming unacceptably institutional. There seems no clinical justification for building wards of more than 15 beds. Single rooms with en-suite facilities should be mandatory for all patients. Even with this provision there will need to be identified women only day areas. We suggested a separate unit with its own entrance and grounds on a district general hospital site as a compromise between strongly held and opposing ideological views.

Multi-professional working is an essential component of current clinical practice. Staffing. including the professional mix, training and numbers, is the basis of both quality of care and also of security within a unit. Any temptation to dilute skill mix (especially in nursing) or to skimp on providing a full range of skills for the care of an increasingly disturbed in-patient population must be resisted.

An environment that is a statement of commitment to quality care is an essential in planning and not an optional extra. Units that are 
pleasant to stay in, and to work in, affect patients and staff and give out important messages about behaviour. Landscaped, safe external space, imaginative lighting, good sound-proofing and thoughtful grading of public and private spaces powerfully influence the atmosphere in a ward. Careful choice of materials and rapid repair and renovation are equally necessary.

The security of a unit involves the provision of an environment that is safe for both patients and staff and which not only is safe, but also feels safe. While people and policies are the main elements in security there are some important design issues. A single point of entry which is manned by reception or security staff is recommended. Closed-circuit television surveillance of non-clinical areas is increasingly acceptable. A designated intensive care area is needed for each unit and (though controversial) an adequately constructed seclusion room should be considered. None of these structural provisions can substitute for appropriately trained staff and well worked-out policies.

The life expectancy (even of modern buildings) is well over $\mathbf{5 0}$ years. Planning for new in-patient units needs to reflect the best available consensus and avoid individual obsessions. Underestimating the level of patient need has been a costly mistake in much recent planning and millennial optimism about the impact of new treatments should be resisted. Skimping on the level of provision (accommodation and finish) is also likely to be a false economy as such buildings suffer more damage and may soon be rendered redundant by an increasingly informed and consumerist public's refusal to accept them. We can learn from our Victorian forebears to have confidence and pride in our professions and ensure that the buildings reflect the importance we place on the care of the most vulnerable in society.

Members of the Working Party: Tom Burns, Chairman of Working Party, Section of Community Psychiatry, St George's Hospital Medical School, University of London. Cranmer Terrace, Tooting, London SWI7 ORE; L. Gargan, L. Walker, S. Heatherington, B. Topping-Morris, C. Vellonoweth, M. Deahl, D. James, N. McDougall and $\mathbf{J}$. Richards

\section{Recent Council Reports}

CR62 'Not Just Bricks and Mortar': Report of the Working Group on the size, staffing, structure, siting and security of new acute adult psychiatric inpatient units, £7.50, April 1998

To inform the planning of new acute in-patient units for adult mental health.

CR63 Gender Identity Disorders in Children and Adolescents: Guidance for Management, £5.00, April, 1998

Offers guidance in the management and therapeutic interventions with children and adolescents and their families.

CR64 Managing Deliberate Self-Harm in Young People, £5.00, April 1998

Provides guidance on managing young people up to the age of 16 (including young people with learning disabilities) who deliberately harm themselves.

A vailable from Book sales, Royal College of Psychiatrists, 17 Belgrave Square, London SW1X 8PG (TEL. +44 (0)171 235 2351, EXTENSION 146). THE LATEST INFORMATION ON COLLEGE PUBLICATIONS IS AVAILABLE ON THE INTERNET AT: www.rcpsych.ac.uk 